\title{
Erythropoiesis in Infants of Diabetic Mothers ${ }^{1}$
}

\author{
KEVIN SHANNON, JACK C. DAVIS, JOHN L. KITZMILLER, SAMUEL A. FULCHER, AND \\ HAROLD M. KOENIG ${ }^{2}$ \\ Department of Pediatrics, Obstetrics and Gynecology and the Clinical Investigtion Center, United States Naval \\ Hospital, Oakland, California 94627; Department of Obstetrics and Gynecology, Children's Hospital of San \\ Francisco, San Francisco, California 94118; and the University of California School of Medicine, San Francisco, \\ California 94143
}

\begin{abstract}
Neonatal polycythemia is a well-established perinatal complication in infants of diabetic mothers (IDM). To investigate the regulation of erythropoiesis in these infants, we measured cord blood erythropoietin (EP) levels by a sensitive radioimmune assay and examined the growth of erythroid progenitor colonies in a series of IDM and control infants. Fifteen of $\mathbf{1 8}$ diabetic mothers were managed on a protocol emphasizing careful glycemic control throughout pregnancy; 10 had glycosolated hemoglobin values within the normal, nondiabetic range during the third trimester. Cord blood EP was elevated in one of 18 IDM and in two of 13 controls ( $p=$ NS). In IDM, cord blood EP values were higher in infants delivered following maternal labor and were inversely correlated with umbilical artery pH $(r=-0.72 ; p=0.006)$. Growth of burst forming units-erythroid was similar in IDM and controls in the presence of 0.1 to $2.0 \mathrm{U}$ of exogenous $\mathrm{EP}$ per $\mathrm{ml}$ of methylcellulose medium. Individual infants tended to respond consistently over the entire range of EP doses tested. The number of burst forming units-erythroid observed did not correlate with cord blood EP, birth weight, or neonatal hematocrits. We conclude that: (a) umbilical cord blood EP levels are generally normal in IDM delivered by mothers in whom good glycemic control is maintained throughout gestation, (b) cord blood EP values are strongly influenced by perinatal events, and (c) the response of erythroid progenitors to EP is intrinsically normal in IDM. These data suggest that polycythemia is an adaptive response in IDM and is not associated with a primary abnormality in erythropoiesis. In addition, because perinatal stress appears to acutely increase cord blood EP, elevated levels in cord blood may not accurately reflect baseline EP release in utero. (Pediatr Res 20: 161-165, 1986)
\end{abstract}

\section{Abbreviations}

EP, erythropoietin

IDM, infants of diabetic mothers

BFU-E, burst forming units-erythroid

FBG, fasting blood glucose

PPBG, postprandial blood glucose

Received July 1, 1985: accepted September 26, 1985.

Correspondence and rauests for reprints LCDR K. M. Shannon, Department of Pediatrics, Naval Hospital, Oakland, CA 94627.

The work reported herein was performed under the United States Navy Clinical Investigation Program Study 84-48-2006.

'The opinions or assertions expressed herein are those of the authors and are not to be construed as official or as necessarily reflecting the views of the Department of the Navy or of the Naval service at large.

${ }^{2}$ Present address: Commanding Officer, United States Naval Hospital, San Diego. CA 92134.
Neonatal polycythemia and hyperviscosity occur with increased frequency in infants who are small for gestational age, in pregnancies complicated by maternal preeclampsia or prolonged gestation, and in IDM (1). Intrauterine hypoxemia has been. proposed as the common underlying metabolic stimulus for increased erythropoiesis in these pregnancies. Studies in gravid. sheep by Zanjani and associates (2-4) have demonstrated that fetal erythropoiesis is regulated by endogenously produced EP and is responsive to a variety of hormonal stimuli. Elevated umbilical cord blood EP levels have been reported in human pregnancies complicated by erythroblastosis fetalis or preeclampsia (5).

Studies in a number of animal models have shown that the metabolic abnormalities present in diabetic pregnancies are associated with a significant reduction in arterial oxygen content and with a reciprocal increase in plasma EP, suggesting a mechanism for polycythemia in IDM (6-9). High cord blood EP levels are present in IDM delivered after intrauterine fetal demise (5), and autopsies of liveborn infants who die during the first $48 \mathrm{~h}$ of life have shown a marked increase in hepatic hematopoietic tissue (10). Widness and co-workers found elevated umbilical cord blood EP levels in $36 \%$ of 61 IDM (7). In their series, EP values correlated with plasma insulin levels, but not with either central venous hematocrit or reticulocyte counts (7).

Analysis of the postulated interrelationship of intrauterine hypoxemia, elevated EP, and polycythemia in IDM is complicated by a number of factors. Because EP is released acutely in response to perinatal stress $(11,12)$, cord blood values may not accurately reflect intrauterine conditions. In addition, erythropoiesis is qualitatively abnormal in IDM $(13,14)$ and may be ineffective (15). Up regulation of insulin receptors on circulating blood cells is observed in diabetic adults and IDM $(16,17)$; the effect of this abnormality on erythropoiesis is unknown.

Over the past decade, in vitro culture systems for erythroid progenitor cells have facilitated laboratory investigation of normal and abnormal erythropoiesis. Colonies derived from early progenitors, termed BFU-E, can be enumerated from human umbilical cord blood (18). Availability of a controlled system in which progenitors can be induced to undergo clonal proliferation and differentiation allowed us to address a number of questions about IDM. We assessed the effectiveness of erythropoiesis at the progenitor level by stimulating burst formation in IDM and controls over a range of EP doses. This approach has been utilized successfully in polycythemia vera to prove the existence of an subset of progenitors which are abnormally sensitive to EP (19). A second experimental goal was to investigate if neonatal hematocrits and reticulocyte counts correlate with BFU-E growth. We reasoned that numbers of circulating BFU-E might be less labile than cord blood EP values and provide a more accurate reflection of fetal erythropoiesis. Finally, we were interested in the effect of careful control of maternal diabetes during preg- 
nancy on cord blood EP, neonatal hematocrit, and BFU-E colony formation.

The experimental design thus allowed us to test the following specific hypotheses related to polycythemia in IDM: (a) that erythropoiesis at the progenitor cell level is normal in IDM and that neonatal polycythemia results from an adaptive response to the intrauterine environment, (b) that a relationship might exist between neonatal hematocrits and the number of BFU-E in cord blood and, (c) that a program emphasizing careful glycemic control of maternal diabetes would result in normal cord blood EP values and in a low incidence of polycythemia in their infants.

\section{METHODS}

Patient population. Study mothers included 15 insulin-dependent diabetic women who were enrolled in a program of emphasizing careful glycemic control during gestation and supervised by one of the authors (JLK). These women, subgrouped according to White's modified classification (20), included six class B women, six class $\mathrm{C}$, and three class $\mathrm{D}$. Three class A diabetic mothers not managed on this protocol were also studied. Control subjects were healthy, nondiabetic mothers admitted for delivery. All control mothers received a $50 \mathrm{~g}$ glucola challenge at $28 \mathrm{wk}$ gestation; serum glucose values $1 \mathrm{~h}$ after glucola were normal in all.

Control infants and IDM had Apgar scores assigned at one and five minutes of age. Two IDM (one each in classes A and C) and one control infant had a 1-minute Apgar score <7; all infants had Apgar scores of at least 7 at 5 min. Gestational age was determined on the basis on maternal dates, confirmed by ultrasound in diabetic women, and later correlated with newborn physical examination. The mean gestational age of control infants was $38.6 \pm 1.7$ and $38.1 \pm 1.3 \mathrm{wk}$ for IDM. The direct Coombs' test was negative in all cord blood specimens. A birth weight index was calculated for all infants by dividing the observed weight by the weight which corresponded to the 50th percentile for that gestational age and sex (21). Macrosomia was defined as a birth weight index of $>1.25$. All mothers enrolled in the study gave informed consent for sampling of umbilical cord blood.

Management of maternal diabetes. All subjects self-monitored capillary blood glucose values with reflectance colorimeters. Testing was carried out at least four times per day, before breakfast and after meals. Six subjects began intensive treatment prior to conception, six in the 1 st trimester, two in the 2 nd trimester, and one woman was initially diagnosed when she presented in diabetic ketoacidosis at $31 \mathrm{wk}$ gestation. A daily diet consisting of $25-35 \mathrm{kcal} / \mathrm{kg}$ of ideal body weight (adjusted for pattern of weight gain) was prescribed. Caloric intake was given as $40-50 \%$ carbohydrate, $75-100 \mathrm{~g}$ of protein; natural fiber was encouraged and the diet was divided as three meals and three snacks. Five subjects were managed by use of continuous insulin-infusion pump therapy, and 10 used a mixture of regular and intermediate insulin divided as two (four women), three (five women), or four (one woman) injections per day. Patients were taught that the goal of the diet-insulin-physical activity regimen was to maintain the FBG between $60-100 \mathrm{mg} / \mathrm{dI}$ and the PPBG between $110-$ $150 \mathrm{mg} / \mathrm{dl}$.

The results of diabetes management were assessed by analysis of mean weekly FBG and PPBG values, measurement of monthly maternal glycosolated hemoglobin levels, and of umbilical cord blood glycosolated hemoglobin at delivery. Women were categorized as being in good control if mean FBG was $<100$ $\mathrm{mg} / \mathrm{dl}$, moderate control if $100-149 \mathrm{mg} / \mathrm{dl}$, and poor if $\geq 150$ $\mathrm{mg} / \mathrm{dl}$; and in good control if mean PPBG was $<150 \mathrm{mg} / \mathrm{dl}$, moderate control $150-199 \mathrm{mg} / \mathrm{dl}$, and poor control if $\geq 200$ $\mathrm{mg} / \mathrm{dl}$.

Laboratory studies. Whole blood, a mixture of arterial and venous blood, was collected from the cut end of the umbilical cord. A small quantity was allowed to clot at room temperature and was refrigerated at $4^{\circ} \mathrm{C}$ tor up to $24 \mathrm{~h}$ before separation of serum. Sera were stored at $-70^{\circ} \mathrm{C}$ before analysis. Erythropoietin was measured by a sensitive radioimmune assay which has been described $(11,22)$.

An additional 5-10 ml of cord blood was collected into $10 \mathrm{ml}$ of heparinized culture medium. These samples were kept at room temperature from $1-24 \mathrm{~h}$ prior to separation of mononuclear cells by Ficoll-Hypaque flotation. Washed mononuclear cells were resuspended at $6 \times 10^{5}$ cells per $\mathrm{ml}$ in Iscove's Modified Dulbecco's Medium for plating in culture medium consisting of $0.8 \%$ methylcellulose supplemented with $30 \%$ fetal calf serum (Flow Laboratories, MacLean, VA; lot 29101036), 1.2\% bovine serum albumen, transferrin, L-glutamine, and a final concentration of $10^{-5} \mathrm{M}$ 2-mercaptoethanol. Commercial colony stimulating factor (GCT Medium, GIBCO, Grand Island, NY; lot $18 \mathrm{~K} 6242$ ) was added to all cultures. Human urinary EP was obtained from the British Columbia Cancer Centre, Vancouver, B.C. The dose-response characteristics of IDM and control mononuclear cells were assessed at EP concentrations between 0.1 and $2.0 \mathrm{U} / \mathrm{ml}$ to evaluate the overall number of circulating progenitors and their sensitivity to EP. Duplicate $35 \mathrm{~mm}$ plates (Falcon, Oxnard, CA) containing $1 \mathrm{ml}$ of methylcellulose medium and a final concentration of $5 \times 10^{4}$ cells per plate were cultured. Colonies derived from BFU-E were enumerated on day 14 by indirect light microscopy using the criteria of Gregory and Eaves (23). Colonies were only scored as derived from BFU-E if they appeared red. In addition, BFU-E were categorized into "early" and "late" maturing subclasses on the basis of the number of discrete clusters identified in individual colonies (23).

Capillary hematocrits were measured by heel puncture within $4 \mathrm{~h}$ of birth in all infants. In addition, automated venous complete blood counts were performed at $4 \mathrm{~h}$ of age in all infants delivered at the Naval Hospital on a Coulter Model $\mathrm{S}^{+}$instrument. Paired capillary and venous hematocrit values were available in $70 \%$ of the infants studied and were closely correlated $(r=0.91 ; p<0.001)$. Specimens collected from the umbilical artery at delivery were submitted for blood gas measurement in 13 IDM. Glycosolated hemoglobin determinations were carried out by the thiobarbituric acid technique as previously described (24).

Paired cord blood specimens for growth of BFU-E and measurement of EP were available on 17 of 18 IDM and on 13 of 17 controls. Sera were not obtained for EP in 5 normal infants and in 1 IDM who had erythroid colony cultures performed.

Statistical analysis. Student's unpaired $t$ test was employed for all statistical analysis, except as noted in the text. Because of the nonparametric distribution of data within the IDM group, comparisons between IDM delivered with and without prior maternal labor were made by applying the Mann-Whitney $U$ test. All means are reported $\pm 1 \mathrm{SD}$ unless otherwise noted.

\section{RESULTS}

Control of maternal diabetes and neonatal findings. All 15 insulin-dependent diabetic mothers in whom glycemic control was carefully monitored delivered liveborn infants between 37 and 39 wk gestation. In these patients, the mean maternal FBG was $110 \pm 17 \mathrm{mg} / \mathrm{dl}$, and mean PPBG was $145 \pm 10 \mathrm{mg} / \mathrm{dl}$ for 20-39 wk. The distribution of mean FBG and PPBG values in the 15 diabetic subjects at different stages of gestation is given in Table 1. By the last 7-9 wk of gestation, control of FBG was good in four women and moderate in the other eleven. Better control of PPBG was achieved, with 13 women classified as in good control and two in moderate control by the end of pregnancy. For the entire group, mean glycosolated hemoglobin for 20-39 wk gestation was $7.4 \pm 1.2 \%$. By the end of pregnancy, maternal glycosolated hemoglobin values were in the normal, nondiabetic range $(<7.6 \%$ of total hemoglobin) in 10 subjects, and were elevated by $0.1-1.2 \%$ of total hemoglobin in five. Six of the 15 insulin-dependent mothers delivered macrosomic neo- 
Table 1. Distribution of mean $F B G$ and $P P B G$ values at different stages of gestation

\begin{tabular}{cccc} 
& $\begin{array}{c}11-19 \\
\text { No. of }\end{array}$ & $\begin{array}{c}20-29 \\
\text { wk }\end{array}$ & $\begin{array}{c}30-39 \\
\text { wk }\end{array}$ \\
\cline { 2 - 3 } diabetic subjects & 12 & 14 & 15 \\
\hline FBG $(\mathrm{mg} / \mathrm{dl})$ & & & \\
$<100$ & 5 & 2 & 4 \\
$100-149$ & 6 & 12 & 11 \\
$\geq 150$ & 1 & 0 & 0 \\
PPBG $(\mathrm{mg} / \mathrm{dl})$ & & & \\
$<150$ & 9 & 10 & 13 \\
$150-199$ & 3 & 4 & 2 \\
$\geq 200$ & 0 & 0 & 0 \\
\hline
\end{tabular}

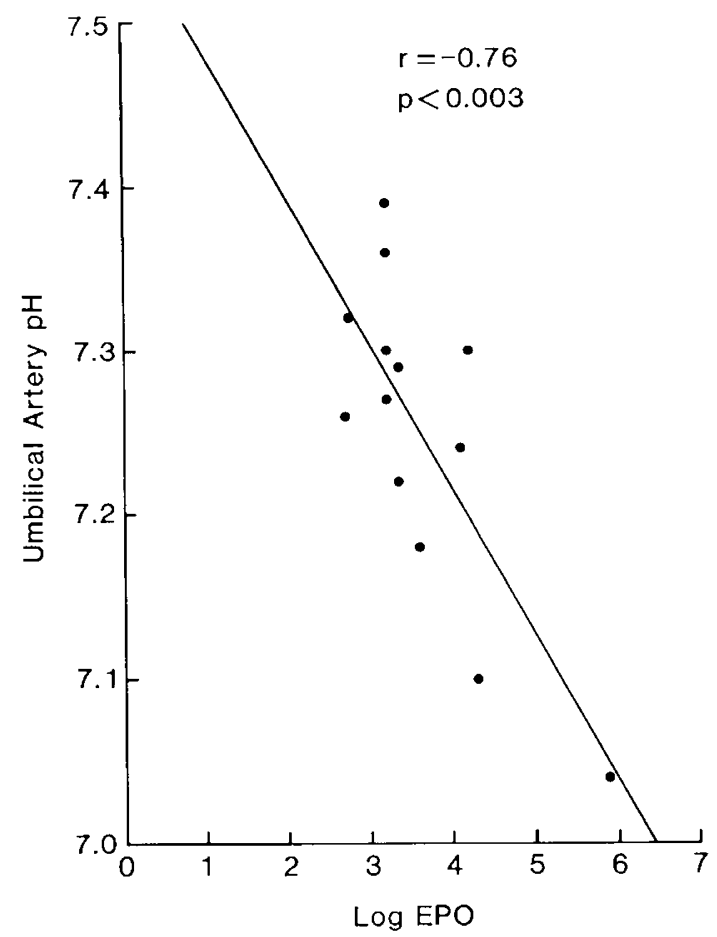

Fig. 1. Correlation of umbilical artery $\mathrm{pH}$ and $\log$ cord blood EP in he 13 IDM in whom both were measured. The observed logarithmic elationship is consistent with previous data on the EP response in normal iubjects (30).

rates, including one of five women with elevated glycosolated remoglobin values at the end of gestation and five of 10 in whom he glycosolated hemoglobin was normal. Two of the three nothers with gestational diabetes delivered infants with macrosomia. Overall, seven of 18 IDM and two of 17 control infants vere macrosomic.

The mean cord blood glycosolated hemoglobin was $4.4 \pm 0.3 \%$ of total hemoglobin (absorbance $0.135 \pm 0.009$ ) in the infants of nsulin-dependent diabetic mothers and $3.6 \pm 0.2 \%$ (absorbance $0.114 \pm 0.003)$ in normal infants $(p<0.05)$. There was no sverlap in the ranges of cord blood glycosolated hemoglobin values in normal infants and IDM.

Mean capillary hematocrit values were $58.5 \% \pm 7.4$ in IDM ind $57.5 \% \pm 8.0$ in controls. One IDM had a hematocrit of $76 \%$ and received a partial exchange transfusion after exhibiting sympoms of hyperviscosity during the first few hours of life. Two ther IDM and two control infants had capillary hematocrits $>65 \%$. None was symptomatic or required partial exchange ransfusion. Hypoglycemia was uncommon; only two IDM re- quired continuous intravenous glucose therapy for serum glucose values $<40 \mathrm{mg} / \mathrm{dl}$.

Erythropoietin values in IDM and control infants. Mean umbilical cord blood EP, determined by radioimmune assay, was $56.3 \pm 83.8 \mathrm{mU} / \mathrm{ml}$ in IDM and $44.4 \pm 36.9 \mathrm{mU} / \mathrm{ml}$ in controls $(p=\mathrm{NS})$. The highest EP value $(362 \mathrm{mU} / \mathrm{ml})$ occurred in an infant of a class $C$ diabetic mother; two control infants had values of 121 and $115 \mathrm{mU} / \mathrm{ml}$, respectively. All other EP values were within normal ranges previously established in this laboratory for caesarian deliveries without labor $(26 \pm 10 \mathrm{mU} / \mathrm{ml})$ and vaginal births $(46 \pm 34 \mathrm{mU} / \mathrm{ml})$ (17). Four infants, all IDM, had cord blood EP values which were in the upper range of normal $(60-80 \mathrm{mU} / \mathrm{ml})$. The patient who required partial exchange transfusion and one other IDM with a one minute Apgar scores $<7$ were in this group. No other infant enrolled in the study had $\mathrm{EP}>45 \mathrm{mU} / \mathrm{ml}$. A strong inverse relationship between umbilical cord blood $\mathrm{pH}$ and EP levels was present in the 13 IDM who had $\mathrm{pH}$ values performed (Fig. 1). A similar inverse correlation was observed between cord blood EP and base deficits calculated from umbilical artery blood gases $(r=-0.75 ; p<0.005)$. Umbilical cord $\mathrm{pH}$ was not measured routinely on controls.

When IDM were stratified according to the presence or absence of maternal labor prior to delivery, infants who were born following labor were noted to have significantly lower umbilical artery $\mathrm{pH}$ and higher cord blood EP values than babies whose mothers were delivered operatively without labor (mean $\mathrm{pH}$ : 7.19 versus $7.30 ; p<0.025$ by Mann-Whitney U; mean EP: 90.7 versus $23.3 ; p<0.005$ by Mann-Whitney $\mathrm{U})$. Because only two control mothers underwent elective caesarian deliveries, meaningful analysis of EP levels in the presence and absence of labor could not be performed in control infants.

Erythroid colony growth. In cultures carried out in the absence of exogenous EP, less than 1 BFU-E derived colony was observed per $10^{5}$ cells plated in both IDM and controls. The range of total BFU-E colonies was similar in both groups at concentrations of EP from 0.1 to $2.0 \mathrm{U} / \mathrm{ml}$ of methylcellulose (Table 2). In addition, the growth of late-maturing, highly proliferative BFU-E were equivalent in both groups. This subclass of BFU-E is thought to derive from an early progenitor cell and requires higher doses of EP for maximal development in vitro (23). Although the number of BFU-E colonies present in cultures varied widely among infants, the response of each patient tended to be consistent over the range of EP doses studied. For individual patients, total BFU-E observed at the lowest dose of exogenous $\mathrm{EP}(0.1 \mathrm{U} / \mathrm{ml})$ correlated well with growth at $2 \mathrm{U} / \mathrm{ml}$, the highest dose tested $(r=0.846 ; p<0.0001$ for control infants and $r=$ $0.919 ; p<0.0001$ for IDM) (Fig. 2). There was no significant relationship observed between the growth of BFU-E and capillary hematocrit, birth weight index or serum EP levels in either controls or in IDM.

\section{DISCUSSION}

Previous studies of the pathogenesis of polycythemia in IDM have focused on the effects of metabolic abnormalities present during diabetic pregnancies on oxygen transport and EP production. The influence of fetal hyperglycemia and hyperinsulinemia on erythropoietin release and erythropoiesis has been investigated in human pregnancies and in a number of animal species. Fetal hyperglycemia leads to decreased blood oxygen content and elevated EP values in fetal sheep $(8,9)$. Experimentally induced fetal hyperinsulinemia also is associated with impaired oxygenation (6), and a relationship between cord blood hyperinsulinemia and increased EP was reported by Widness et al. (7). The observation that reduction in arterial $\mathrm{pO}_{2}$ and oxygen saturation correlate with increased glycosolated hemoglobin levels during gestation in diabetic women provides further evidence that chronic hyperglycemia decreases oxygen availability (25). The capacity of the human fetus to respond to chronic intrauterine hypoxemia by releasing EP is suggested by reports showing 
Table 2. Growth of erythroid progenitor colonies derived from BFU-E*

\begin{tabular}{|c|c|c|c|c|}
\hline \multirow{2}{*}{$\begin{array}{l}\text { Exogenous } \\
\text { EP }(\mathrm{U} / \mathrm{ml})\end{array}$} & \multicolumn{2}{|c|}{ Control } & \multicolumn{2}{|c|}{ IDM } \\
\hline & Late BFU-E & Total BFU-E & Late BFU-E & Total BFU-E \\
\hline 0.1 & $6.0 \pm 3.2$ & $30.4 \pm 12.2$ & $3.3 \pm 1.4$ & $30.8 \pm 9.2$ \\
\hline 0.25 & $9.8 \pm 3.7$ & $54.3 \pm 16.5$ & $8.9 \pm 2.7$ & $62.6 \pm 16.7$ \\
\hline 1.0 & $27.7 \pm 10.2$ & $96.9 \pm 22.6$ & $23.3 \pm 6.3$ & $116.9 \pm 23.0$ \\
\hline 2.0 & $26.6 \pm 8.3$ & $103.6 \pm 16.1$ & $30.6 \pm 8.4$ & $113.2 \pm 23.1$ \\
\hline
\end{tabular}

* Results expressed as number of BFU-E per $10^{5}$ mononuclear cells plated \pm SEM.

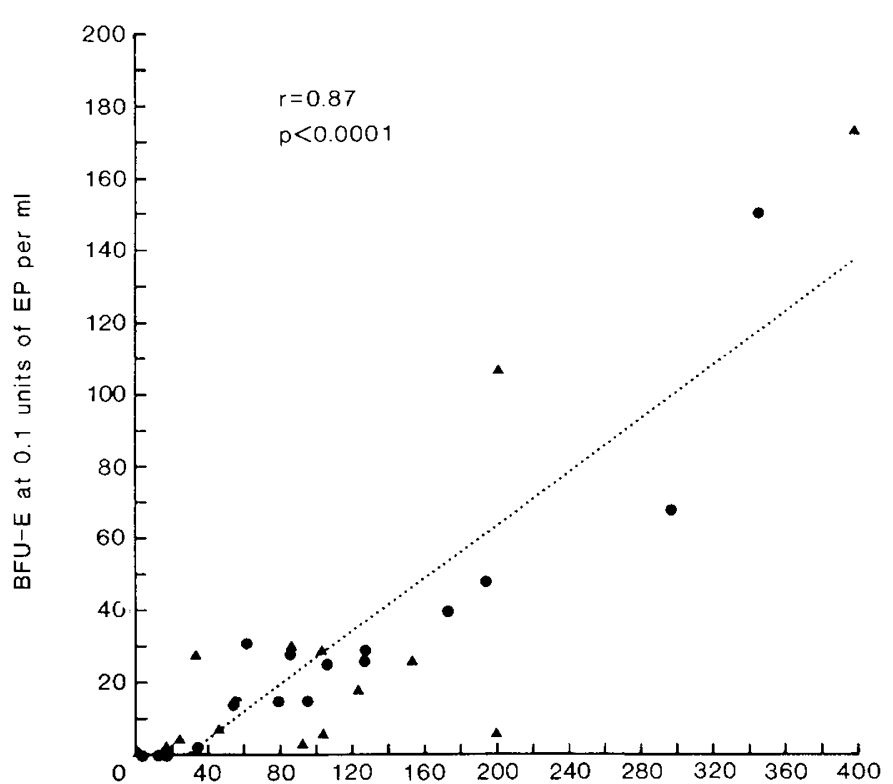

BFU-E at 2.0 units of EP per $\mathrm{ml}$

Fig. 2. Relationship of BFU-E growth at the lowest $(0.1 \mathrm{U} / \mathrm{ml})$ and highest $(2.0 \mathrm{U} / \mathrm{ml})$ EP test concentrations. There was an approximate three-fold increase in total BFU-E in both IDM (O) and control (A) subjects observed between 0.1 and $2.0 \mathrm{U} / \mathrm{ml}$. For all patients, the number of colonies present at $0.1 \mathrm{U} / \mathrm{ml}$ of EP was highly predictive of growth in plates receiving $2.0 \mathrm{U} / \mathrm{ml}(p<0.0001)$. Data were not available for two IDM and two control infants at $0.1 \mathrm{U} / \mathrm{ml}$ of EP. All four had normal hematocrits and normal growth at $2 \mathrm{U} / \mathrm{ml}$ of EP.

elevated cord blood EP levels in pregnancies complicated by erythroblastosis fetalis, preeclampsia, and maternal diabetes $(5$, $7)$, and the acute stress of normal labor has been associated with increased cord blood EP $(11,12)$. The increased incidence of polycythemia in infants born at high altitudes (26) provides additional evidence implicating hypoxemia in its pathogenesis.

The converging evidence that hyperglycemia and hyperinsulinemia reduce blood oxygen content and stimulate the production of fetal EP suggests a mechanism for polycythemia in IDM. However, a number of issues have not been resolved. Widness et al. (7) reported that over one-third of IDM had elevated EP levels in cord blood; however, EP levels did not correlate with neonatal hematocrit values. A recent study of 10 IDM (five with polycythemia) did not reveal any with elevated EP in cord blood (13). In addition, EP levels were not correlated with neonatal hematocrits in the IDM we examined. This lack of association between cord blood EP values and polycythemia may be explained in part by the kinetics of the erythroid response to EP. Serum EP values fall dramatically in patients with sickle cell anemia a few hours after beginning supplemental oxygen therapy and rise measurably within 3 hours of its discontinuation (27). Changes in reticulocyte counts do not occur until 2-3 days later (27). Meberg (28) produced hypoxemia in fetal rats by exposing their mothers to low concentrations of inspired oxygen for periods between $6 \mathrm{~h}$ and 8 days. Elevated plasma EP values were noted by $6 \mathrm{~h}$ in fetal rats; however, after 8 days of hypoxemia plasma EP was normal in both infants and mothers while hematocrits were increased. Taken together with our finding that umbilical cord EP and $\mathrm{pH}$ were inversely related, these experimental results suggest that neonatal polycythemia is an endproduct of chronic intrauterine hypoxemia while cord blood EP values are strongly influenced by intrapartum stress.

An alternative explanation for the observation that cord blood EP values do not correlate with hematocrits in IDM is that the erythroid response to EP is blunted. Stevenson et al. (15) found increased pulmonary excretion of carbon monoxide in IDM and suggested that this might reflect ineffective erythropoiesis. Recent reports that the switch from fetal to adult hemoglobin synthesis is delayed in IDM provides additional evidence that erythropoiesis is qualitatively abnormal in these infants (23). We tested the hypothesis that polycythemia in IDM is a secondary response to conditions in the fetal environment, rather that the result of a primary abnormality of hematopoietic cells by examining the growth of erythroid progenitors in vitro. We observed that the total number of BFU-E cultured and the dose-response curve over a range of exogenous EP doses were comparable in IDM and controls. These data suggest intrinsically normal erythroid proliferation in IDM and support the hypothesis that polycythemia in these infants is a secondary phenomenon, rather than the result of a primary hematopoietic abnormality. Although a wide range of BFU-E growth was observed in both IDM and controls, individual patients showed a consistent pattern of response in the presence of varying amounts of EP. The finding that subjects tended to be either high, low, or normal responders over the entire range of exogenous EP studied supports differences in the actual number of erythroid progenitors present, rather than variable sensitivity of progenitors to EP. Factors that regulate the number of colony-forming cells in the fetal circulation have not been determined; however, we observed no correlation of gestational age, maternal diabetes, or capillary hematocrit with the growth of BFU-E derived colonies. Only a few infants in our series had hematocrits in excess of $65 \%$ and it is possible that a relationship between neonatal hematocrits, EP values, and burst formation might have been apparent if more polycythemic newborns had been available for study.

The low frequency of elevated cord blood EP values we observed contrasts with the data of Widness and associates (7) who found increased cord blood EP in 22 of 61 IDM. Serum EP values were determined by an identical method in the same reference laboratory and the infants enrolled in both studies were nonasphyxiated by the criteria of Apgar scores. A potentially important difference is that good biochemical control of maternal diabetes was emphasized in the mothers we studied. Careful management of maternal glucose metabolism during gestation perhaps minimized the amount of chronic hypoxic stress due to hyperglycemia and/or hyperinsulinemia in our patients. The low incidence of polycythemia in our patients might have resulted from the elimination of a major intrauterine stimulus for $\mathrm{EP}$ release. However, it is important to emphasize that normoglycemia was not achieved in the IDM we studied as cord blood glycosolated hemoglobin values were higher and macrosomia was more frequent than in controls. 
Our data emphasize the influence of intrapartum stress on cord blood EP values and suggest that a complex set of factors contribute to EP levels in IDM. We believe that the release of $\mathrm{EP}$ in utero is important in the pathogenesis of neonatal polycythemia, but our results suggest that cord blood EP values may not accurately reflect fetal erythropoiesis. Amniotic fluid EP has recently been shown to be increased in IDM and in infants delivered by hypertensive mothers and does not appear to be influenced as much by the events of labor as cord blood EP (29). A prospective study that controls for the influence of labor and other acute perinatal factors on cord blood EP or which examines amniotic fluid EP will be required to directly address the effects of intrauterine hyperglycemia on fetal EP production. If careful glycemic control during gestation reduces the degree of fetal hypoxemia, the incidence of perinatal complications may decrease. A sensitive and widely available method of measuring fetal EP in high-risk pregnancies may permit the early identification of some infants who are experiencing significant intrauterine hypoxemia.

Acknowledgments. The authors are indebted to John Pacely for superb technical support. Drs. Connie and Alan Eaves provided encouragement and made many helpful suggestions. We thank Mary Gavin, Ph.D., for performing statistical analysis, Joan Carter for preparing the figures, and Scott Hambly, Ph.D., for valuable editorial assistance. Cord blood erythropoietin assays were kindly performed by Gisela K. Clemons, Ph.D., at the Lawrence Berkeley Laboratory, University of California, Berkeley, CA.

\section{REFERENCES}

1. Oski F, Naiman JL 1982 Hematologic Problems of the Newborn. Saunders Co, Philadelphia, pp 87-96

2. Zanjani ED. Mann LI. Burlington H, Gordon AS, Wasserman LR 1974 Evidence for a physiologic role of erythropoietin in fetal erythropoiesis. Blood 44:285-290

3. Zanjani ED. Banisadre M 1979 Hormonal stimulation of erythropoietin production and erythropoicsis in anephric sheep fetuses. J Clin Invest 64:11811187

4. Zanjani ED, Ascensao JL, McGlave PB, Banisadre M, Ash RC 1981 Studies on the liver to kidney switch of erythropoietin production. J Clin Invest 67:1183-1188

5. Finne PH 1966 Erythropoietin levels in cord blood as an indicator of intrauterine hypoxia. Acta Pediatr Scand 55:478-489

6. Carson BS. Philipps AF, Simmons MA. Battaglia FC, Meschia G 1980 Effects of sustained insulin infusion upon glucose uptake and oxygenation of the bovine fetus. Pediatr Res 14:147-152

7. Widness JA Susa JB, Garcia JF Singer DB, Sehgal P, Oh W Schwartz R. Schwart HC 1981 Increased erythropoiesis and elevated erythropoietin in infants born to diabetic mothers and in hyperinsulinemic rhesus fetuses. $\mathbf{J}$ Clin Invest 67:637-642

8. Philipps AF. Dubin JW. Matty PJ, Raye JR 1982 Arterial hypoxemia and hyperinsulinemia in the chronically hyperglycemic fetal lamb. Pediatr Res 16:653-658

9. Philipps AF Widness JA, Garcia JF, Raye JR, Schwartz R 1982 Erythropoietin elevation in the chronically hyperglycemic fetal lamb. Proc Soc Exp Biol Med 170:42-47

10. Naeye RL 1965 Infants of diabetic mothers: a quantitative, morphologic study. Pediatrics 35:980-988

11. Widness JA Clemons GK. Garcia JF Oh W. Schwartz R 1984 Increased immunoreactive erythropoietin in cord serum after labor. Am $\mathrm{J}$ Obste Gynecol 148:194-197

12. Stevenson DK, Bucalo LR, Cohen RS, Vreman HJ, Clemons GK, Ferguson JE II, Schwartz HC 1985 Increased immunoreactive erythropoietin in cord plasma and neonatal bilirubin production in normal term infants after labor. Clin Res 33:114A

13. Perrine SP, Greene MF, Faller DV 1985 Delay in the fetal globin switch in infants of diabetic mothers. N Engl J Med 312:334-338

14. Bard H, Prosmanne J 1985 Relative rates of fetal hemoglobin and adult hemoglobin synthesis in cord blood of infants of insulin-dependent diabetic mothers. Pediatrics 75:1143-1147

15. Stevenson DK, Bartoletti AL, Ostrander CR, Johnson JD 1979 Pulmonary excretion of carbon monoxide in the human infant as an index of bilirubii production. II. Infants of diabetic mothers. J Pediatr 94:956-958

16. Neufeld ND, Kaplan SA, Lippe BM 1981 Monocyte insulin receptors in infants of strictly controlled diabetic mothers. J Clin Endocrinol Metab 52:473-476

17. Dons RF, Ryan J, Gordon P, Wachslicht-Robbard H 1981 Erythrocyte and monocyte insulin binding in man. Diabetes 30:896-902.

18. De Alarcon PA, Lyle VA, Stockman JA III 1982 In vitro erythroid cultures of cord blood of normal newborns. Pediatr Res 14:532

19. Eaves CJ, Eaves AC 1978 Erythropoietin (Ep) dose-response curves for threo classes of erythroid progenitors in normal human marrow and in patients with polycythemia vera. Blood 52:1196-1210

20. White P 1974 Diabetes mellitus in pregnancy. Clin Perinatol 1:331-347

21. Williams RL, Creasy RK, Cunningham GC, Hawes WE, Norris FD. Tashiro M 1982 Fetal growth and perinatal viability in California. Obstet Gynecol $59: 624-632$.

22. Garcia JF, Ebbe SN, Hollander L, Cutting HO, Miller ME. Cronkite EP 1982 Radioimmunoassay of erythropoietin: Circulating levels in normal and polycythemic human beings. J Lab Clin Med 99:624-634

23. Gregory CJ, Eaves AC 1977 Human marrow cells capable of erythropoictic differentiation in vitro: Definition of three erythroid colony responses. Bloor 49:855-864

24. Sosenko JM Kitzmiller JL, Fluckiger R Loo SWH Younger DM Gabbay KH 1982 Umbilical cord glycosylated hemoglobin in infants of diabetic mothers: Relationships to neonatal hypoglycemia, macrosomia, cord serum C-peptide. Diabetes Care 5:566-570

25. Madsen H, Ditzel J 1982 Changes in red blood cell oxygen transport in diabetic pregnancy. Am J Obstet Gynecol 143:421-424

26. Stevens K, Wirth FH 1980 Incidence of neonatal polycythemia at sea Ievel. J Pediatr $97: 118-119$

27. Embury SH, Garcia JF, Mohandas N, Pennathur-Das R, Clark MR 198. Effects of oxygen inhalation on endogenous erythropoictin kinetics, crythropoiesis, properties of blood cells in sickle-cell anemia. $N$ Engl J Med 311:291-295

28. Meberg ^ 1980 Plasma erythropoietin levels in fetal and newborn rats: responsi to hypoxia. Exp Hematol 8:615-619

29. Tcramo KA, Widness JA, Clemons GK, Saarinen R, Voutilainen P, Schwart R 1985 Amniotic fluid erythropoictin in high risk pregnancies. Pediatr Res 19:164A

30. Adamson JW 1968 The erythropoietin/hematocrit relationship in normal and polycythemic man: implications of marrow regulation. Blood 32:597-609 